Article

\title{
Optimal Configuration of Energy Storage System Coordinating Wind Turbine to Participate Power System Primary Frequency Regulation
}

\author{
Junhui Li ${ }^{1, *}$, Yunbao Ma ${ }^{1}$, Gang Mu ${ }^{1}$, Xichao Feng ${ }^{2}$, Gangui Yan ${ }^{1}$, Gan Guo ${ }^{1}$ and \\ Tianyang Zhang ${ }^{1}$ \\ 1 Department of Electrical Engineering, Northeast Electric Power University, Jilin 132012, China; \\ mybstu@163.com (Y.M.); mg@neepu.edu.cn (G.M.); yangg@neepu.edu.cn (G.Y.); \\ guogan@outloook.com (G.G.); wonder3152610@163.com (T.Z.) \\ 2 Shenyang Power Supply Bureau, State Grid Liaoning Electric Power Company Limited, \\ Shenyang 110811, China; fxcisme@163.com \\ * Correspondence: lijunhui@neepu.edu.cn
}

Received: 2 May 2018; Accepted: 24 May 2018; Published: 30 May 2018

\begin{abstract}
Large scale wind power integration has a negative influence on the frequency response. Assistant measurement improves the frequency stability of power systems under high wind penetration. The Proportional Curtailment Strategy (PCS) for wind turbines provides a primary frequency reserve for power systems. To solve the worthless curtailed wind power, the PCS is used to improve the utilization of wind power curtailment. Then the wind turbine and the lithium battery Energy Storage System (ESS) provide primary frequency reserves together. Different control strategies of ESS have been proposed based on the different methods for selecting valid reserves. The economic benefits of different control strategies have been compared based on the same frequency regulation reserve. The optimal control strategy is the maximum method. The economic benefit of the maximum value method is $¥ 4,445,300$.
\end{abstract}

Keywords: wind power; primary frequency regulation; energy storage system; optimal control strategy

\section{Introduction}

In recent years, fossil fuels such as coal, oil, and so on are drying up all over the world. In [1-4], the problems of climate warming and environmental pollution are becoming more and more serious. In this context, the generation of renewable power has developed rapidly. Wind power is representative of renewable energy. The cumulative installed capacity of global wind power has grown at a remarkable rate between 2005 and 2017, averaging near 22\% per annum. Research on wind power generation started early and the technology has matured in some European countries. In [5], the proportion of the installed wind turbine in Europe is higher than other regions. Although the Chinese wind power industry started late, it has developed rapidly with the support of the "renewable energy law" and other related policies. In June 2012, Chinese wind power installed capacity had exceeded the United States, and China became the world's first in wind power generation. In [6], the accumulative installed capacity of wind power in China had reached $149 \mathrm{MW}$, which accounted for $8.6 \%$ of the total installed capacity by the end of 2016. Therefore, wind power had become the third major power source after thermal power generation and hydropower generation. In [7-9], wind power also brought some problems when it was incorporated into the power system, such as frequency regulation, voltage regulation, and power system stability.

The mainstream wind turbine does not have the abilities of inertial response and auxiliary frequency regulation. When large scale wind power replaces traditional power sources, the inertia 
response of the power system must be reduced. Increasing wind power penetration weakens the frequency regulation ability of the power system. And the increasing wind power penetration brings severe challenges to the safe and stable operation of the power system. In $[10,11]$, the Power Grid Companies of many countries and regions clearly require that wind power generation must provide the frequency regulation ability.

In [12], the focus was on the modeling of wind turbines equipped with direct drive permanent magnet synchronous generators for fundamental frequency power system simulations. But neither of these two methods can cope with the rapid change of frequency in the power system containing wind power. In [13], they studied the dynamic schedule and control strategies (DSCS) of the renewable energy aggregators (REA) under the complementary characteristics of the small-scale renewable energy generators. But REA must use ESS to guarantee the power system's frequency regulation ability. In order to have the reserve capacity of wind turbines for frequency regulation, many researchers put forward many technical methods (rotor speed control, variable pitch control, and so on) to conduct the wind power curtailment. And in [14], they propose a control strategy which combines rotor speed control and variable pitch angle control to increase the frequency regulation ability of the wind farm. But these methods will reduce the economic benefit of the wind farm. In $[15,16]$, due to the random and intermittent nature of wind energy, the reliability of the frequency supported by the wind turbine is difficult to guarantee. After the fault is cleared, the wind turbine, which had participated in the power system's frequency regulation, should be restored to the optimum speed as soon as possible. Thus, the wind turbine will absorb some active power from the power system, which may cause the twice frequency drop. In [17], taking into account the frequency regulation of wind turbines, they enhance the frequency modulation ability of wind turbines by virtual inertia. Therefore, the frequency response capability of wind turbines needs to be further strengthened.

The large scale Energy Storage System has the ability of energy translation in space and time and has a very fast response speed. With the application of energy storage technology in power systems, the frequency stability of wind power would be broadly improved. In [18], the researchers studied how wind farms and energy storage systems provide a primary frequency regulation service for the power system. Their simulation example aims at optimal economic efficiency of the wind farm and energy storage system. There are many constraints for simulation, such as the entire system's power balance, the control method of the wind turbine, and the energy storage system when they participate in frequency regulation and the operation constraints of the energy storage system. Finally, the optimal capacity and power of ESS are given by the results of the example analysis. In order to benefit from the wind farm and ESS, this article also pointed out that the policy support from grid company is very important. In [19], this article analyzed the frequency characteristics of power systems under high wind power permeability. The paper presents a "virtual inertia" that provides a rapid response for the power system by using supercapacitor energy storage. This measure can prevent the frequency from dropping to the threshold of the low frequency load shedding, and improve the frequency stability of power system. In [20], it assumes that the battery energy storage system had been installed in the power system with high wind power penetration. Aiming at the battery energy storage system participating in the frequency control, the SOC feedback control method is proposed in this paper. In [21], they considered that the ESS provided the frequency regulation service for the power system with high wind power permeability. This method will lead to a phenomenon where the configuration capacity of ESS will exceed the actual demand. Therefore, the economics of wind farms and ESS in those articles need to be improved. In [22], this paper proposes the concept of the virtual energy storage system (VESS), which includes conventional energy storage systems, flexible loads, distributed generators, multi-vector energy systems, and so on. In this paper, the states (Ton and Toff) of switch in VESS are similar to the charge and discharge of ESS. Therefore, VESS can provide frequency regulation ability.

The ESS can coordinate the wind turbine, which is helpful to frequency regulation. The introduction of an energy storage system can increase the economic benefits of wind farms 
and improve the frequency response ability of wind turbines. This paper proposes the proportional curtailment strategy for wind farms. The application of this strategy will provide partial primary frequency regulation energy. In $[23,24]$, the requirement of the primary frequency regulation was that the active power can be output within $15 \mathrm{~min}$, continuously. The utilization index of the wind curtailment has been established in this paper. This indicator is used to evaluate the utilization degree of the wind curtailment. In this paper, it is considered that the proportional curtailment strategy for the wind farm will produce a part of the useless wind curtailment. The two kinds of control strategies of ESS are determined by the different selection methods of the effective reserve capacity. On the premise of providing the same frequency regulation reserve, this article compared the economy of the two control methods. At the end of the article, this paper chooses the configuration method of the ESS with the better economy.

\section{Reserve Method of the Primary Frequency Regulation for Wind Turbines}

\subsection{Principle of the Proportional Curtailment Strategy for Wind Turbines}

The principle of the proportional curtailment strategy for wind turbines is a way to set up an upward adjustment margin for primary frequency regulation. The significance of this method is that the wind farm will curtail wind power according to a certain proportion. The relationship between the output power of the proportional curtailment strategy and the actual maximum generator power is shown in Equation (1):

$$
P_{\text {curtailed }}(t)=(1-\alpha) P_{\text {avail }}(t)
$$

where $P_{\text {curtailed }}(t)$ is the power of the wind curtailment and $\alpha$ is the ratio coefficient of wind curtailment, $\alpha \in(0,1)$. The specific value of $\alpha$ depends on the wind farm's reserve capacity by the requirement of the power grid dispatching department. $P_{\text {avail }}(t)$ is the instantaneous maximum power output.

The schematic diagram belonging to the proportional curtailment strategy is shown in Figure 1. In Figure $1, P_{\text {rate }}$ is the rated capacity of the wind farm. At present, the wind power control technology enables the wind farm to output power at a certain percentage of the maximum output [25]. However, the realization of the proportional curtailment strategy also depends on the application of basic control methods such as virtual inertial control and droop control. The proportional curtailment strategy for wind farms can provide an uninterrupted primary frequency regulation reserve. The reserve capacity can be provided by this method. And the reserve capacity varies with the maximum transmittable power of the wind.

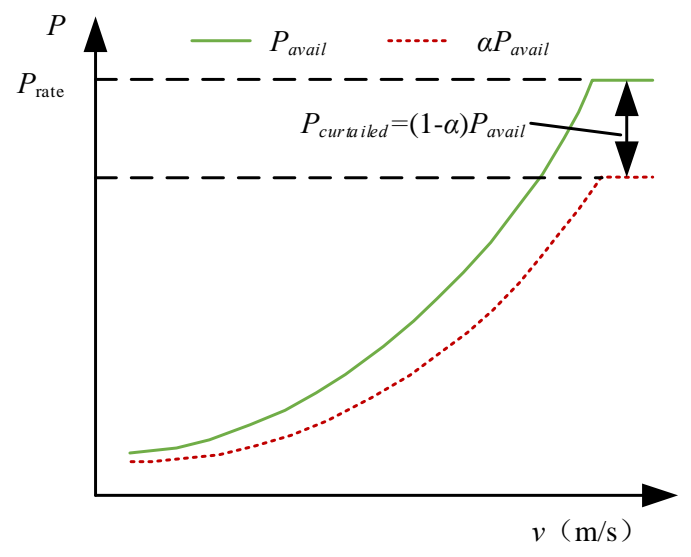

Figure 1. Diagram of the proportional curtailment strategy.

\subsection{Reserve Requirements of the Primary Frequency Regulation}

There are different requirements for primary frequency regulation reserved in the power systems around the world. Such as the German EON Power Grid Corp [26], they required that the reserve 
capacity of the frequency regulation, which was provided by the generators, must be fully released within $30 \mathrm{~s}$ when the active power produces fluctuations. They also require that the output power of the frequency regulation reserve could maintain more than $15 \mathrm{~min}$ and the output power can be continuously output at a certain level. These measures can cooperate with the second and the third frequency regulation of the power system. The purpose of these measures is to restore power system frequency to normal range as soon as possible.

Within $15 \mathrm{~min}$, the output power of the wind farm varies with the wind speed. From Equation (1), it can be known that when the coefficient of wind curtailment $\alpha$ is a fixed value and the maximum power of wind farms is changeable, the capacity of the wind curtailment by the proportional curtailment strategy also will be changeable. In order to make sure of how much the reserve of the primary frequency regulation by the wind farms can be provided within the $15 \mathrm{~min}$, the minimum capacity of the wind curtailment within the $15 \mathrm{~min}$ is necessary. The effective reserve capacity of the wind farms $R_{\text {avail }}$ can be seen in Equation (2) and the schematic diagram is shown in Figure 2.

$$
R_{\text {avail }}=\min \left[\bigcup_{t=t_{0}}^{t_{0}+14} P_{\text {curtailed }}(t)\right]
$$

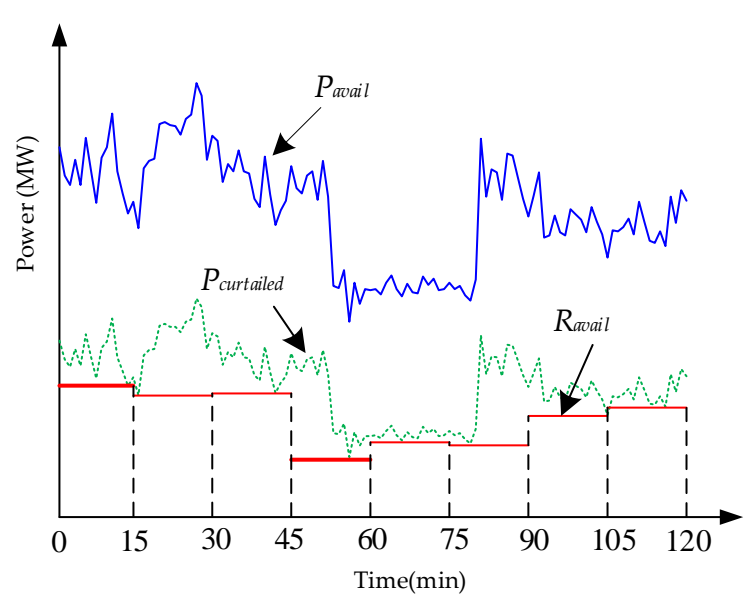

Figure 2. Diagram of the effective reserve capacity.

\subsection{Assessment of the Utilization Rate of the Wind Curtailment}

As shown in Figure 2, the capacity of the proportional curtailment strategy for wind farms $P_{\text {curtailed }}$ cannot directly represent the actual effective capacity of the effective reserve capacity of the wind farms $R_{\text {avail }}$. The difference between the $P_{\text {curtailed }}$ curve and the $R_{\text {avail }}$ curve can not provide the frequency regulation reserve for the power system. In order to analyze the utilization of the wind power under the proportional curtailment strategy, the utilization rate of wind curtailment $\eta$ is defined in this paper. Equation (3) is an expression of the utilization rate of the wind curtailment:

$$
\eta=\frac{R \times t}{\int_{0}^{t} P_{\text {curtailed }}(t) \mathrm{dt}} \times 100 \%
$$

The higher utilization rate of the wind curtailment means less waste of wind power and higher efficiency of the primary frequency regulation reserve.

\section{The Capacity Configuration Method of the ESS}

Due to the inherent fluctuations of wind power and the demand of the primary frequency regulation for the power system within $15 \mathrm{~min}$, the wind farm that adopts the proportional curtailment 
strategy will produce a lot of useless wind power, which will reduce the utilization rate of wind curtailment. In order to ensure the economic operation of the wind farm, this paper needs to take some measures to improve the utilization rate of the wind curtailment and the ability of wind farms that participated in the primary frequency regulation of the power system. For the wind farm and the energy storage system, the application of the proportional curtailment strategy also can provide the frequency regulation reserve for the power system. This measure can achieve several goals, such as meeting the requirements of the frequency regulation, reducing the energy of the wind curtailment, improving the utilization rate of wind curtailment, and increasing the economic benefits of wind farms.

\subsection{Control Strategy of the ESS}

In order to realize the control method with more beneficial effects, this paper proposes two control strategies to participate in the primary frequency regulation for the energy storage system and the wind farm.

- $\quad$ Maximum value method

In order to meet the requirement that the system outputs the active power continuously within $15 \mathrm{~min}$, the maximum capacity of the wind curtailment in $15 \mathrm{~min}$ is selected as the effective reserve capacity $R_{\text {avail. }}^{A}$ Equation (4) is as follows:

$$
R_{\text {avail }}^{A}=\max \left[\bigcup_{t=t_{0}}^{t_{0}+14} P_{\text {curtailed }}(t)\right]
$$

where $P_{\text {curtailed }}$ is the power of the proportional curtailment strategy. Its schematic diagram is shown in Figure 3.

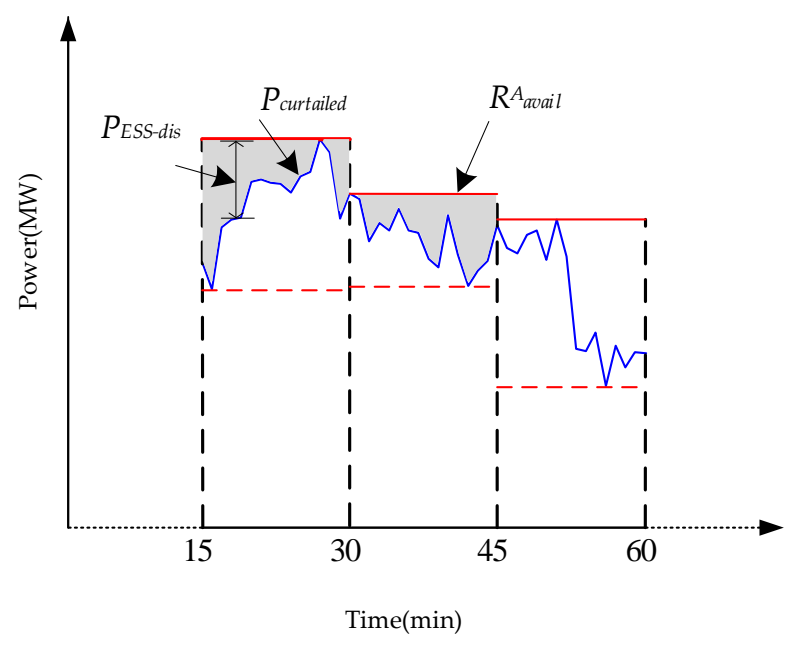

Figure 3. Maximum value control strategy of ESS.

When the wind farm and the energy storage system are involved in primary frequency regulation, the discharge power of the energy storage system is $P_{E S S-d i s:}$

$$
P_{E S S-d i s}=R_{\text {avail }}^{A}-P_{\text {curtailed }}
$$

The shadow part of the first two $15 \mathrm{~min}$ in Figure 3 is the discharge of the energy storage system.

It can be known from the operating principle of the actual power system that the primary frequency regulation reserve of the power system is released only when the power system has greater power or frequency fluctuation. Therefore, if the power system does not have large power fluctuations during the scheduling cycle, the power system does not need the wind farm to provide the frequency 
regulation reserve. At this time, the discharge power of the energy storage system is $P_{E S S-d i s}=0$, as shown in the third 15 min set in Figure 3. In this case, the energy storage system does not move, there is no shadow part, and the discharge of ESS is 0.

When the power system does not require the wind farm to provide the frequency regulation reserve, the ESS is charged with the rated power until the SOC of the energy storage system is 1. Therefore, the energy storage system, which is combined with the wind farm, participates in the primary frequency regulation of the power system.

When the maximum value method is not used, the power system only relies on wind farms for primary frequency regulation, as is shown in Figure 2 and Equation (2). At this point, the effective reserve capacity within $15 \mathrm{~min}$ is the minimum value of the discarded wind capacity. The energy storage system and the wind farm participate in the primary frequency regulation together by using the control maximum method. And the effective reserve capacity within $15 \mathrm{~min}$ is the maximum of the wind curtailment. Therefore, while the same reserve capacity is provided for the primary frequency regulation, the reduction of the wind curtailment capacity by the maximum value method is $P_{\text {curt-reduced }}$ :

$$
P_{\text {curt-reduced }}^{A}=R_{\text {avail }}^{A}-R_{\text {avail }}
$$

The area between the red full line and the red dash line in Figure 3 is the power loss of the wind curtailment by the maximum method in each scheduling cycle, which is named $E_{\text {curt-reduced }}^{A}$.

- $\quad$ Mean value method

The condition of applying the proportional curtailment strategy is to satisfy the primary frequency regulation reserve. And the wind farms can continuously output power within $15 \mathrm{~min}$. The average value of the wind curtailment within $15 \mathrm{~min} R_{\text {avail }}^{B}$ is chosen as the effective reserve capacity:

$$
R_{\text {avail }}^{B}=\frac{\sum_{i=1}^{n} P_{\text {curtailed }}(i)}{n}
$$

where $n$ is wind power data point within $15 \mathrm{~min}, P_{\text {curtailed }}(i)$ represents the corresponding capacity of the wind curtailment at the $i$ moment, and its schematic diagram is shown in Figure 4 . The slant shadows are the discharge of ESS in the first and third $15 \mathrm{~min}$. The point shadows are the charge of ESS in the first and third $15 \mathrm{~min}$.

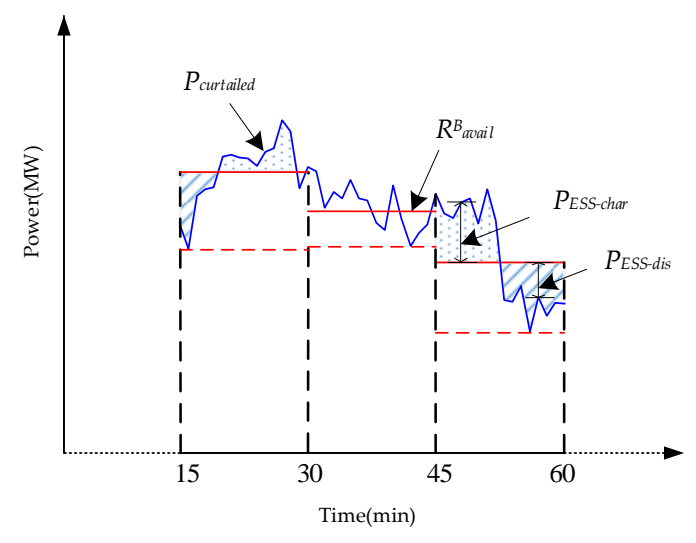

Figure 4. Mean value method control strategy of ESS.

When wind farms with ESS participate in the primary frequency regulation together, the discharge power of the energy storage system is as follows:

$$
P_{E S S-d i s}=R_{\text {avail }}^{B}-P_{\text {curtailed }}\left(R_{\text {avail }}^{B} \geq P_{\text {curtailed }}\right)
$$


The charging power of the energy storage system is as follows:

$$
P_{E S S-c h a r}=P_{\text {curtailed }}-R_{\text {avail }}^{B}\left(R_{\text {avail }}^{B}<P_{\text {curtailed }}\right)
$$

When the power system requires the wind farm to provide the frequency regulation reserve, there is no larger power fluctuation in a scheduling cycle. Under these circumstances, the wind farm does not need to release the primary frequency regulation reserve. So the charge and discharge of the energy storage system are $P_{E S S-c h a r}=P_{E S S-d i s}=0$, as shown in the second $15 \mathrm{~min}$ in Figure 4 . In this case, the energy storage system does not move. There is no shadow part. The charge and discharge capacity of ESS are 0.

In order to ensure that the energy storage system and wind farm can participate in primary frequency regulation together, method 2 uses the mean value method. In other words, the effective reserve capacity within each $15 \mathrm{~min}$ is the average of the wind curtailment capacity. When the mean value method can provide the same reserve capacity for the primary frequency regulation, the mean value method can reduce capacity of the wind curtailment and it is indicated by $P_{\text {curt-reduced }}$ :

$$
P_{\text {curt-reduced }}^{\mathrm{B}}=R_{\text {avail }}^{\mathrm{B}}-R_{\text {avail }}
$$

The area between the red real line and the red dotted line in Figure 4 is the reduction of the wind curtailment by the mean method in each scheduling cycle and it is indicated by $E_{\text {curt-reduced }}^{B}$. The control strategy flowchart is shown in Figure 5.

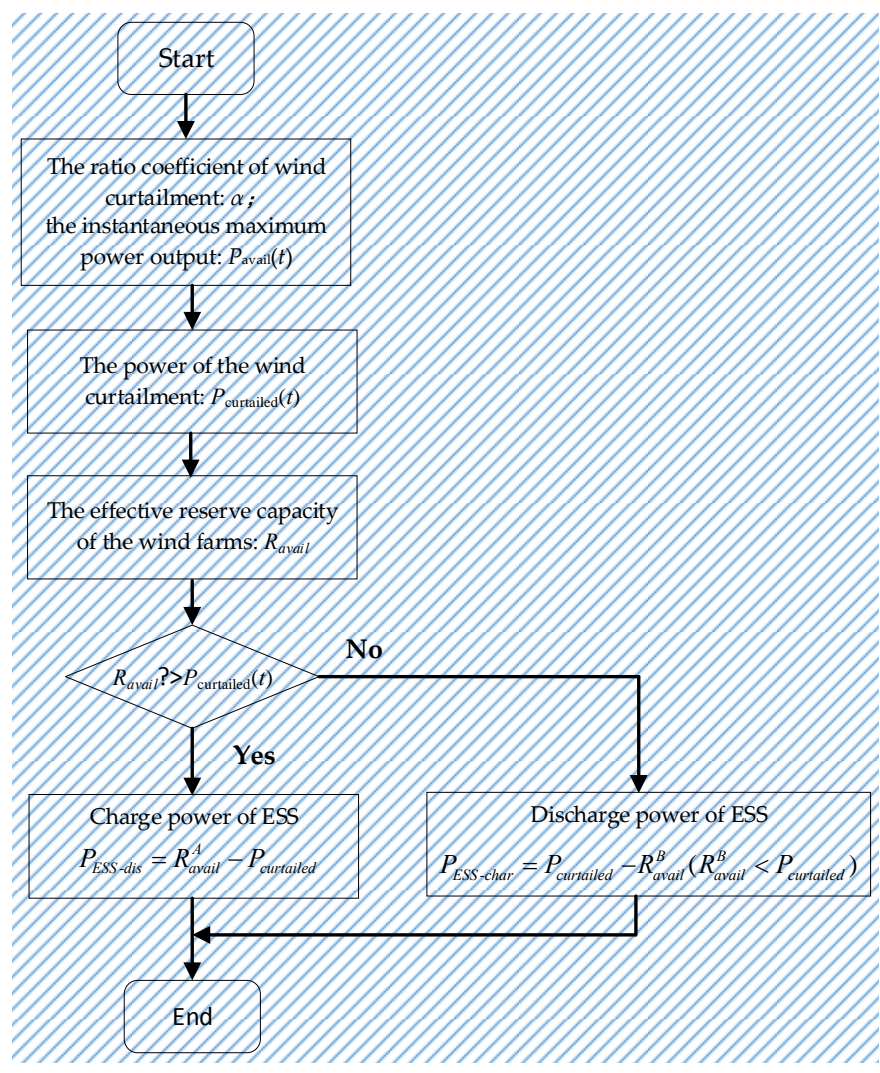

Figure 5. Flowchart of the mean value method.

\subsection{Capacity Configuration Method of the ESS}

The capacity configuration of the lithium battery includes two aspects: the power capacity and energy capacity of the ESS. This section introduces the method for determining the power capacity and energy capacity of ESS. 
- $\quad$ Rated power capacity: $P_{\text {rate }}$

In view of the importance of the primary frequency regulation at high wind power penetration, the time that the energy storage system assists the wind farm to provide primary frequency regulation must be determined. In this paper, the charge power and discharge power of the two control strategies are determined at first. Then the charge power and discharge power are analyzed by statistical analysis. In view of the economy of the energy storage system, the rated power of the maximum value method and the mean value method are $P^{A}{ }_{\text {rate }}$ and $P^{B}$ rate, respectively. Then, the discharge power of the energy storage system for the maximum value method is $P_{E S S-d i s}$ with a confidence of $99 \%$ :

$$
P_{\text {ESS-dis }}= \begin{cases}R_{\text {avail }}^{A}-P_{\text {curtailed }} & \left|P_{E S S-d i s}\right| \leq P_{\text {rate }}^{A} \\ P_{\text {rate }}^{A} & \left|P_{E S S-d i s}\right|>P_{\text {rate }}^{A}\end{cases}
$$

The charge power and discharge power of the energy storage system by the average value method is represented as $P_{E S S}$, and is shown in the Equation (12):

$$
\left|P_{E S S}\right|= \begin{cases}\left|R_{\text {avail }}^{B}-P_{\text {curtailed }}\right| & \left|P_{E S S}\right| \leq P_{\text {rate }}^{B} \\ P_{\text {rate }}^{B} & \left|P_{\text {ESS }}\right|>P_{\text {rate }}^{B}\end{cases}
$$

- Rated energy capacity $E_{\text {rate }}$

In consideration of many constraints, such as the charge and discharge of ESS, the economy of ESS, the rated power capacity: $P^{A}{ }_{\text {rate }} / P^{B}$ rate, and so on, the corresponding rated energy capacity $E^{A}$ rate and $E^{B}$ rate, under two control strategies, are determined with the confidence of $99 \%$.

Taking into account the benefits of the lithium battery energy storage system, the final configuration result is the one that has both the better economic mean value method and maximum value method. The increase of the economic benefit of the wind farms before and after installing ESS is $F^{x}$ :

$$
F^{x}=f_{1}^{x}-f_{c}^{x}-f_{m}^{x}(x=A / x=B)
$$

where $x=A$ represents the maximum value method, and $x=B$ represents the mean value method. Under the two strategies, the economic benefit that energy storage reduces using wind curtailment power is $f_{1}{ }^{x}, f_{c}{ }^{x}$ is the investment cost of the energy storage system, and $f_{m}{ }^{x}$ is the maintenance cost of ESS.

The combination of Equations (6) and (10), and the scene that the power system requires for the wind farm to provide the frequency regulation reserve, can be known where the economic benefits of the energy storage reduce the wind curtailment, and is shown as follows:

$$
f_{1}^{x}=\sum_{i=1}^{n} E_{\text {curt-reduced }}^{x}(i) \cdot C_{w}
$$

where $n$ is the number of times that requires the wind farm to provide the frequency regulation reserve, $E_{\text {curt-reduced }}^{x}$ is the reduced power of the wind curtailment at $i$ time under the two strategies, and $C_{w}$ is the electricity price when the wind power is incorporated into the power system.

The investment cost of energy storage system is $f_{c}{ }^{x}$ :

$$
f_{c}^{x}=C_{p} P_{\text {rate }}^{x}+C_{e} E_{\text {rate }}^{x}
$$

where $C_{p}$ is the investment cost of the unit charge/discharge power of the energy storage system, $C_{e}$ is the investment cost of unit capacity of energy storage system, and $P^{x}$ rate and $E^{x}$ rate are the rated power and capacity of the energy storage system under two control strategies, respectively. 
The operation and maintenance cost of the energy storage system is $f_{m}{ }^{x}$ :

$$
f_{m}^{x}=\sum_{t=1}^{k} C_{m} P_{\text {rate }}^{x}
$$

where $C_{m}$ is the annual maintenance cost for the unit charge/discharge power of the energy storage system, and $k$ is the total lifetime of the energy storage system (year).

After comparing $F^{A}$ with $F^{B}$, the control strategy with the better economic outlook is adopted as the capacity of ESS in this paper.

\section{Example Analysis}

\subsection{Example Condition}

The maximum load of the power system in Northeast China in 2012 is 2155.9 MW, the maximum unit capacity is $200 \mathrm{MW}$, the installed wind turbine in this area is $700 \mathrm{MW}$. The rated frequency is $50 \mathrm{~Hz}$. The effectiveness of the control methods are analyzed based on the measured data of wind power and load in 2012 (1 January 2012-12 December 2012, the sampling interval is $1 \mathrm{~min}$ ).

\subsection{Simulation Time}

The load and wind power in the power system vary with time. Therefore, the wind power permeability and response ability of the power system are different at different times. And the requirement for the primary frequency regulation reserve is also changed. It can determine the period that the power system needs for the wind farm to provide frequency reserve.

Based on multiple typical load scenarios (i.e., different permeability of the wind power), it is assumed that the unit with $200 \mathrm{MW}$ (the maximum stand-alone capacity of the power system) falls off in the system. When the unit falls off and the lowest frequency of the system is equal to the low-frequency load shedding limit $(49.5 \mathrm{~Hz})$, the simulation system is shown in Figure 6.

In Figure 6, $\mathrm{K}$ is the coefficient of the frequency regulation under the different rate of the wind power penetration with the same perturbation. At the same time, the wind power permeability will also change the inertial response coefficient of the power system, such as "Transfer Fcn1".

Their corresponding penetration rate of the wind power is shown in Table 1 by MATLAB/Simulink (R2014b).

Table 1. Corresponding relationship of load and wind power penetration.

\begin{tabular}{cccc}
\hline $\boldsymbol{P}_{\boldsymbol{L}}(\mathbf{M W})$ & Penetration Rate $\%$ & $\boldsymbol{P}_{\boldsymbol{L}}(\mathbf{M W})$ & Penetration Rate $\%$ \\
\hline 2160 & 40.2 & 1860.5 & 28 \\
2000 & 34 & 1839.9 & 27.2 \\
1904.8 & 30 & 1798.6 & 25.4 \\
1877.9 & 29 & 1777.8 & 24.4 \\
\hline
\end{tabular}

According to the data in Table 1, the relationship between the load and limit value of wind power permeability is fitted by the curve fitting toolbox in MATLAB. The fitting relationship is shown in Equation (17):

$$
W P L_{\lim }=-\frac{1521.68}{P_{L}}+109.98 \%
$$




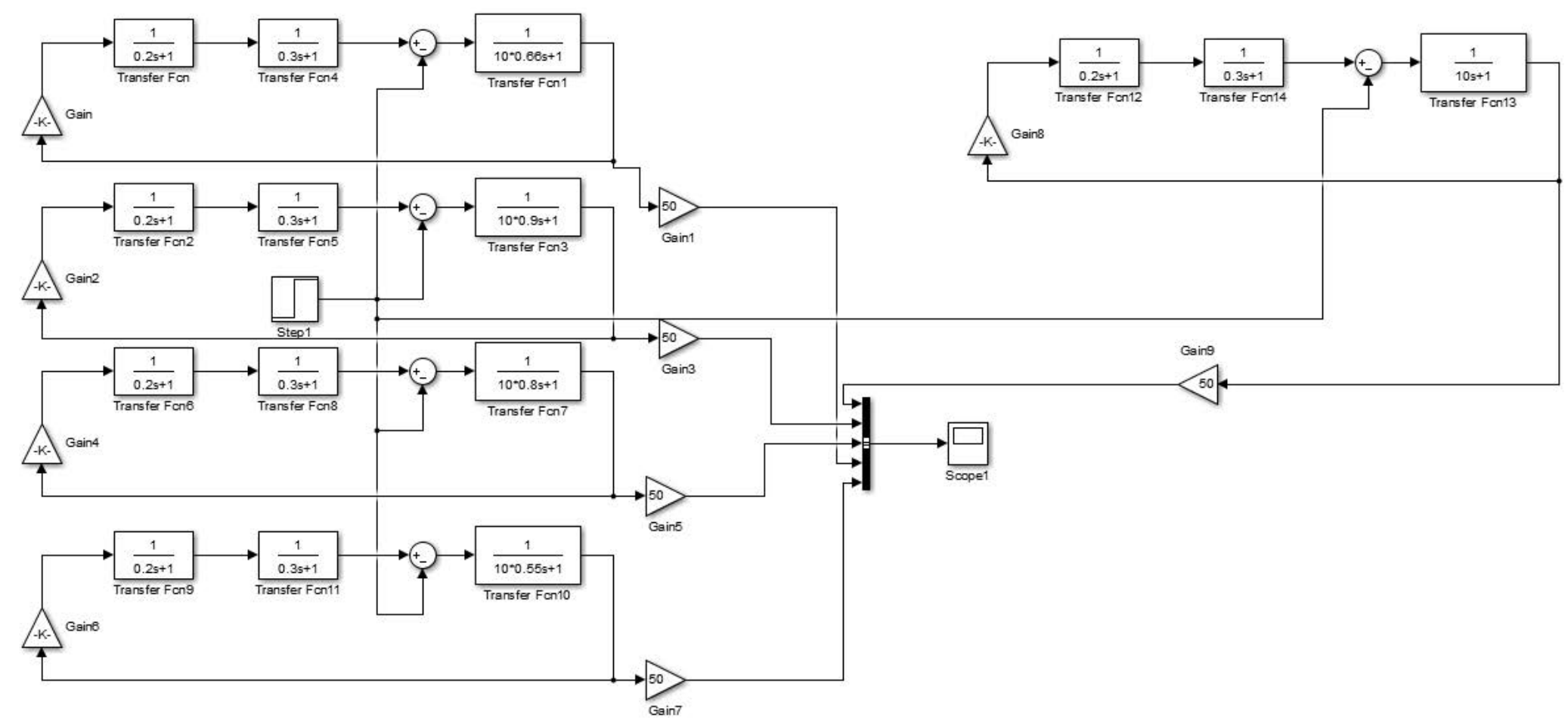

Figure 6. A block diagram of the primary control for frequency regulation. 
According to Equation (17), when the power falls off (200 MW) and the lowest frequency is equal to the low frequency load shedding limit, the limit value of the corresponding wind power penetration is $W P L_{\text {lim }}$. According to $W P L_{\text {lim }}$, it is possible to determine whether the wind farm was required to provide the frequency regulation reserve at any time in the load scene. The method is described as follows. Based on real wind power and load data, the wind power permeability WPL $(t)$, at any time $t$, can be calculated. Due to the higher penetration of wind power in the power system, the frequency regulation of the power system is weaker. If the corresponding wind power permeability $W P L_{\text {lim }}(t)<W P L(t)$ and the maximum single power $(200 \mathrm{MW})$ is dropping, the lowest frequency of the system will be lower than the low frequency load shedding limit. At this time, the wind farm is required to provide the frequency regulation reserve for the power system. On the other hand, there is no need for wind farms to provide the frequency regulation reserve. Finally, the simulation results show that the total of 2818 scheduling periods requires the wind farm to provide the frequency regulation reserve.

\subsection{Configuration Method of the ESS}

This section analyzes the wind curtailment power under different control strategies. This section also determines the power and energy capacity of the corresponding energy storage system. The rated power and energy capacity of the energy storage system are determined by comparing the economics of each control strategy. The configuration process of ESS's capacity is shown in Figure 7. (X = A: Maximum value method; $X=B$ : Mean value method).

- Analysis the power of wind curtailment under different control methods

The simulation determines the capacity that all wind farms in this area need to provide the primary frequency regulation reserve in each scheduling period. And the ratio coefficient of the wind curtailment $\alpha$ varies with the change of the primary frequency regulation reserve. Based on the simulation condition, which is the same primary frequency regulation reserve, the simulation results are as follows: the wind curtailment power by the method of the proportional curtailment strategy for the wind farms without the energy system, the wind curtailment power of the maximum value method for ESS, and the wind curtailment power of the mean value method for ESS. These results are shown in Table 2. The maximum value method reduced 1106.5 MWh and the mean value method reduced 706.8 MWh in the same year compared with the wind farms without ESS.

- The rated power of energy storage system

When the maximum value method is adopted, the discharge power of the frequency regulation reserve is determined according to Equations (4) and (5), and the maximum value is $29.93 \mathrm{MW}$ and the minimum value is 0 . The cumulative probability distribution of the discharge power amplitude is calculated, and the statistical results are shown in Figure 8. According to the statistical results, the rated power of the energy storage system is $29.93 \mathrm{MW}$, which can meet the power system demand of $100 \%$. However, the requirement of the energy storage system over $5.8 \mathrm{MW}$ is only $1 \%$ under the maximum method (as shown in the red line mark in the figure). If the rated power of the energy storage system greatly increases because of the small probability events, the economy of the energy storage system will be seriously affected. Therefore, $P^{A}{ }_{\text {rate }}=5.8 \mathrm{MW}$.

When the mean value method is adopted, the charging power and discharging power of ESS are determined according to the Equations (7)-(9). The cumulative probability distribution statistics of the charge and discharge events are shown in Figure 8. As shown in the diagram, the probability of discharge power at $3.5 \mathrm{MW}$ is only $1 \%$. Taking into consideration the economy of the energy storage system, we find that $P^{B}$ rate $=3.5 \mathrm{MW}$.

- The rated energy capacity of the energy storage system 
According to the charging and discharging power of the energy storage system within the different control methods, the primary frequency regulation reserve of the energy storage system can be determined. And the simulation counts the cumulative probability distribution of the energy storage capacity. When the maximum value method is adopted, the cumulative probability distribution of the energy storage capacity is shown in Figure 9. The energy storage capacity is over 1.25 MWh, with only $1 \%$ under the maximum value method. Thus, $E^{A}$ rate $=1.25 \mathrm{MWh}$.

When the mean method is adopted, the accumulative probability distribution of energy storage capacity is shown in Figure 9 The energy storage capacity with mean value method is over $0.37 \mathrm{MWh}$, with only $1 \%$. Thus, $E^{B}$ rate $=0.37 \mathrm{MWh}$.

Table 2. Curtailed wind energy and utilization of different control methods.

\begin{tabular}{cccc}
\hline Control Strategy & Without ESS & Maximum Value Method & Mean Value Method \\
\hline wind curtailment energy(MWh) & 8267.2 & 7160.7 & 7560.4 \\
Utilization rate of wind curtailment $(\eta)$ & $91.45 \%$ & $100 \%$ & $100 \%$ \\
\hline
\end{tabular}

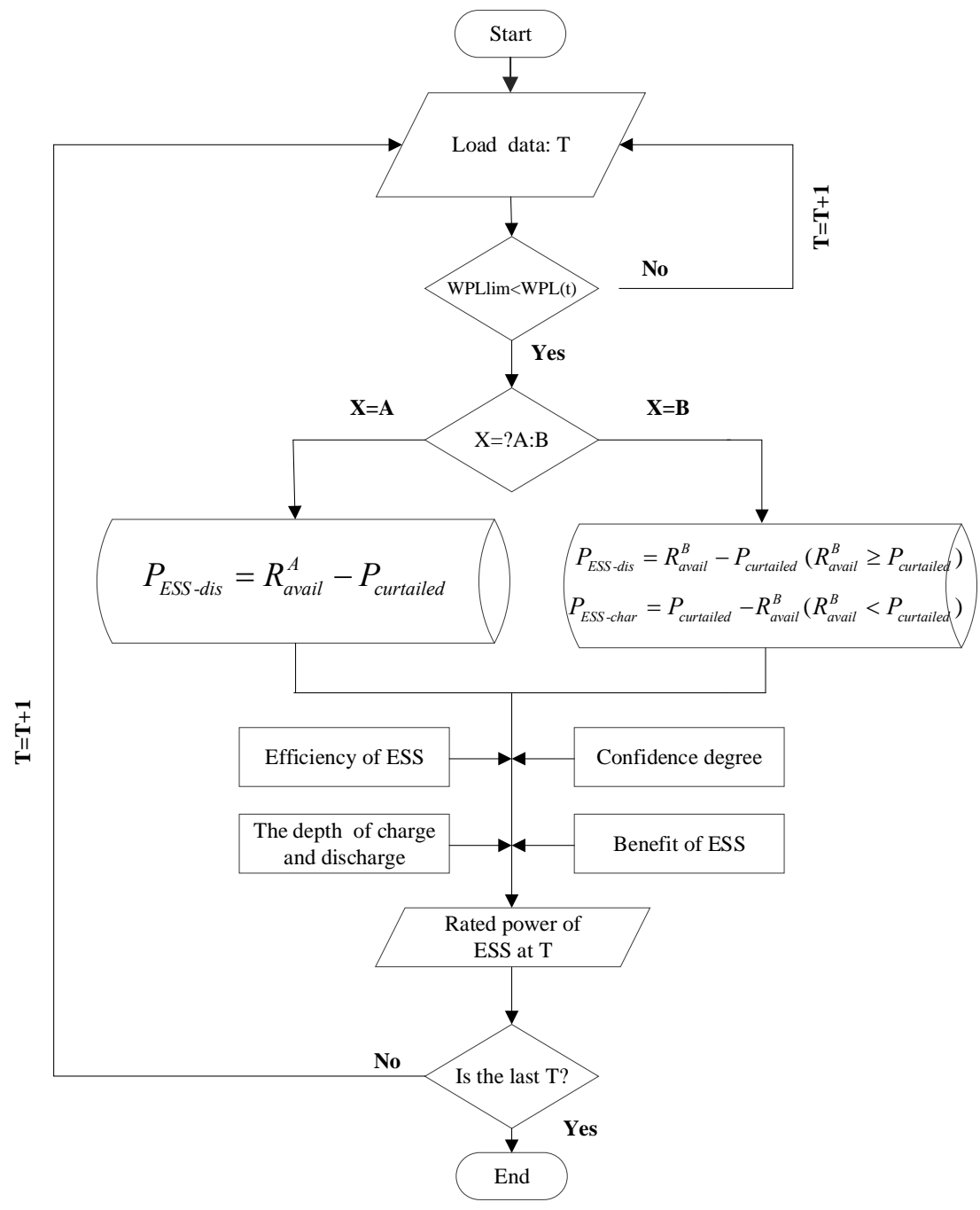

Figure 7. The configuration process of ESS's capacity.

To sum up, the rated power of the energy storage system is 5.8 MW under the maximum value method. And the rated power of the energy storage system is 3.5 MW under the mean value method. When the efficiency of the energy storage system and the depth of discharge are not considered, the energy capacity of the two control strategies is 1.25 MWh and 0.37 MWh, 
respectively. The charge/discharge efficiency of the lithium battery is $90 \%$, and the discharge interval is [0.2,1] [27]. When the efficiency of the energy storage system and the depth of discharge are considered, the energy capacity of the two control strategies are $E^{A}{ }_{\text {rate }}=1.25 / 0.9 /(1-0.2)=1.74 \mathrm{MWh}$ and $E^{B}$ rate $=0.37 / 0.9 /(1-0.2)=0.51 \mathrm{MWh}$, respectively. The configuration results are shown in Table 3.

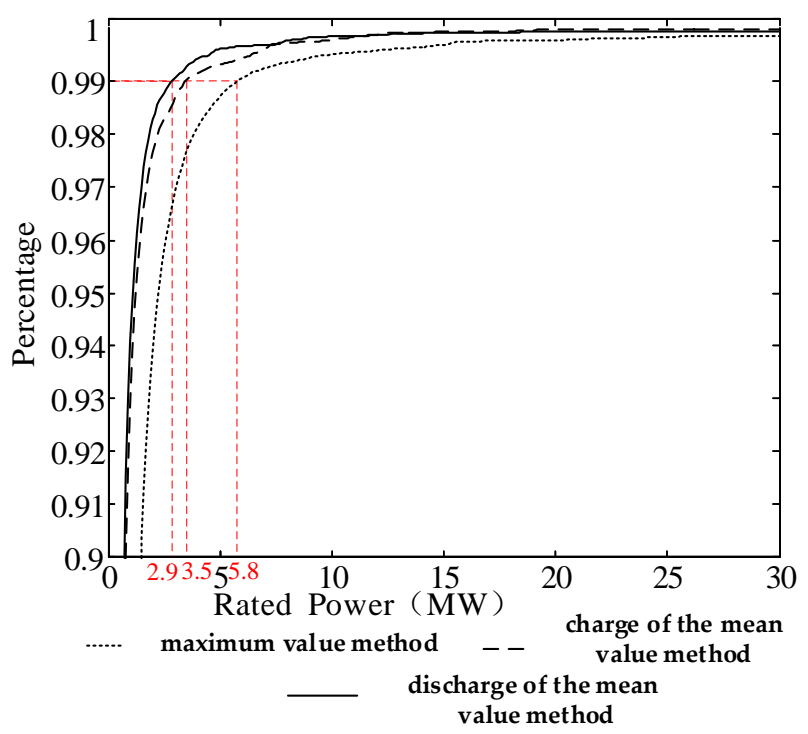

Figure 8. Cumulative probability distribution of the power of ESS using two strategies.

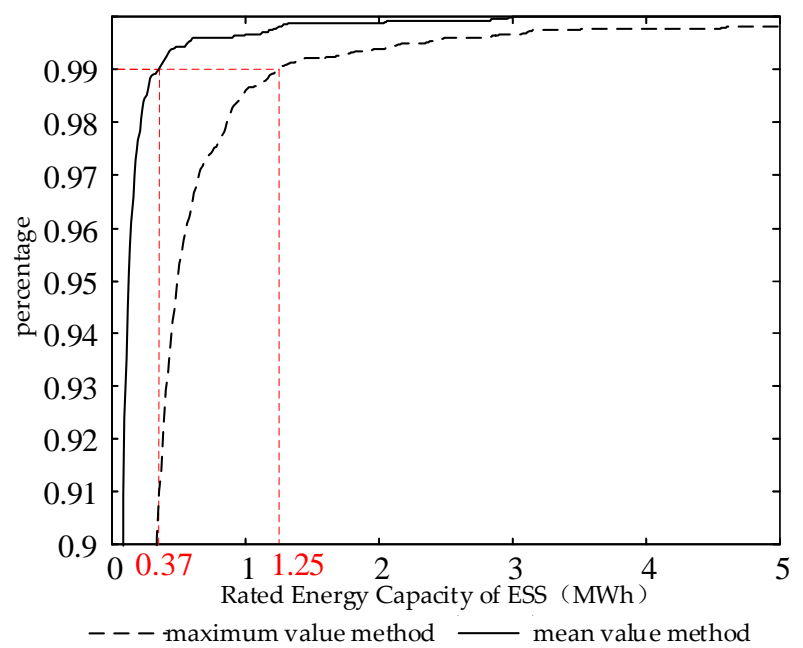

Figure 9. Cumulative probability distribution of energy of ESS in the two strategies.

Table 3. The rated power and energy capacity of different control strategies.

\begin{tabular}{ccc}
\hline Control Strategy & Maximum Value Method & Mean Value Method \\
\hline rated power of ESS (MW) & 5.8 & 3.5 \\
rated energy capacity of ESS (MWh) & 1.74 & 0.51 \\
\hline
\end{tabular}

\subsection{Configuration Results of the ESS}

The wind power tariff is $C_{w}=6000$ yuan/MWh. The lithium battery energy storage system unit charge/discharge power investment cost is $C_{p}=2.739$ million yuan/MW; The unit capacity investment costs of lithium battery energy storage system is $C_{e}=1.344$ million yuan/MWh; The lithium battery unit charge/discharge power of the annual operation and maintenance costs is 64,000 yuan/MW.a. 
The lithium battery life is $T=10 \mathrm{a}[28,29]$. In view of the possibility of large power shedding is very small in the power system and the energy storage system only starts work when the larger power shedding, therefore, the power loss can be neglected. The economic comparison of the two control strategies is shown in Table 4.

Table 4. Economical comparison of two control strategies.

\begin{tabular}{ccccc}
\hline Control strategy & $\boldsymbol{F}^{x}$ & $\boldsymbol{f}_{\mathbf{1}}$ & $f_{c}$ & $f_{\boldsymbol{m}}$ \\
\hline$x=A$ (million yuan) & 444.53 & 663.9 & 182.25 & 37.12 \\
$x=B$ (million yuan) & 298.98 & 424.1 & 102.72 & 22.4 \\
\hline
\end{tabular}

It can be known from Table 4 that $F_{A}>F_{B}$, and the maximum value method has better economic benefits. So, the provisioning results that the energy storage system and wind farm provide the frequency regulation reserve for the power system are as follows: Rated power is $P_{\text {rate }}=5.8 \mathrm{MW}$, and Rated energy capacity is $E_{\text {rate }}=1.74 \mathrm{MWh}$.

\section{Conclusions}

This paper has proposed that the wind turbines provide the frequency regulation reserve for the power system by using the proportional curtailment method. According to the different selection methods of effective frequency regulation capacity $R_{\text {avail }}$ for wind farms, two control strategies of energy storage system assisted wind turbines to provide the frequency regulation reserve. At the same time, the method of the charging, discharging power, and capacity of the energy storage system are determined. Based on the measured data of wind power and load in a certain area, the capacity configuration method of ESS is proposed. Considering the economic benefits of the two strategies, this paper determines the energy storage capacity. Example analysis shows that method 1 can achieve 145.55 million yuan profit compared with method 2. The control method proposed in this paper has great significance for reducing wind curtailment and increasing the frequency reserve capacity of wind farms. But the frequency regulation revenue may need to be updated and iterated on as the frequency regulation market continues to evolve. Whether or not the proposed method is applicable to all regions is the next research focus.

Author Contributions: J.L., G.M. and G.Y. proposed this study. Y.M. and X.F. wrote the paper. G.G. and T.Z. reviewed and edited the manuscript. All authors read and approved the manuscript.

Acknowledgments: The authors gratefully acknowledge the support of the National Natural Science Foundation of China (No.U1766204), National Key R\&D Program of China (2017YFB0902200), Science and Technology Project of State Grid Corporation of China (Key Technology and Application of Grid Connected Operation of Large Capacity Battery Energy Storage Power Station), Industrial Innovation of Jilin Province Development and Reform Commission (2017C017-2), Jilin Provincial “13th Five-Year Plan" Science and Technology Project ([2016] 88) for this work.

Conflicts of Interest: The authors declare no conflict of interest.

\section{References}

1. Gangui, Y.; Hongzhe, L.; Gang, M.; Yuan, T. Crowding-out Effect of Wind Power under Special Condition and Comprehensive Evaluation on Energy-Saving and Emission Reduction Benefits of Wind Power Generation. J. Power Syst. Technol. 2012, 36, 51-56.

2. Lou, S.; Wu, Y.; Cui, Y.; Yi, L.; Wang, J.; State Key Laboratory of Advanced Electromagnetic Engineering and Technology, Huazhong University of Science and Technology; Electric Power Economic Research Institute; State Grid Shanghai Municipal Electric Power Company. Operation Strategy of Battery Energy Storage System for Smoothing Short-term Wind Power Fluctuation. J. Autom. Electr. Power Syst. 2014, 38, 17-22.

3. Bo, L.; Zhijia, H.; Hao, J. Wind Power Status and Development Trends. J. Northeast Electr. Power Univ. 2016, $36,7-13$. 
4. Mao, Y.; Chunlin, Y. Research on Wind Power Real-Time Forecasting Based on Fuzzy Granular Computing. J. Northeast Electr. Power Univ. 2017, 37, 1-7.

5. Tao, X. Statistics of wind power installed in Europe in 2016. Wind Energy Ind. 2017, 7, 9.

6. National Energy Administration. Operation of Wind Power in the first quarter of 2017. J. Acta Energies Sol. Sin. 2017, 5, 76.

7. Yao, W.; Jiang, L.; Wen, J.; Wu, Q.; Cheng, S. Wide-Area Damping Controller for Power System Interarea Oscillations: A Networked Predictive Control Approach. J. IEEE Trans. Control Syst. Technol. 2015, 23, 27-36. [CrossRef]

8. Hazari, R.; Mannan, M.A.; Muyeen, S.M.; Tamura, J. Stability Augmentation of a Grid-Connected Wind Farm by Fuzzy-Logic-Controlled DFIG-Based Wind Turbines. J. Appl. Sci. 2018, 8, 20. [CrossRef]

9. Li, C.; Cao, P.; Li, J.; Zhao, B. Review on reactive Voltage Control Methods for Large-Scale Distributed PV Integrated Grid. J. Northeast Electr. Power Univ. 2017, 37, 82-88.

10. Cho, S.M.; Yun, S.Y. Optimal Power Assignment of Energy Storage Systems to Improve the Energy Storage Efficiency for Frequency Regulation. Energies 2017, 1012, 2092. [CrossRef]

11. Tang, X.; Miao, F.; Qi, Z.; He, H.; Wu, T.; Li, S.; Institute of Electrical Engineering, Chinese Academy of Sciences; North China Electric Power Research Institute Co., Ltd. Survey on frequency control of wind power. J. Proc. CSEE 2014, 34, 4304-4314.

12. Bonfiglio, A.; Delfino, F.; Invernizzi, M.; Procopio, R. Modeling and Maximum Power Point Tracking Control of Wind Generating Units Equipped with Permanent Magnet Synchronous Generators in Presence of Losses. Energies 2017, 10, 102. [CrossRef]

13. Zhang, S.; Mishra, Y.; Shahidehpour, M. Utilizing distributed energy resources to support frequency regulation services. J. Appl. Energy 2017, 206, 1484-1494. [CrossRef]

14. Díaz-González, F.; Hau, M.; Sumper, A.; Gomis-Bellmunt, O. Coordinated operation of wind turbines and flywheel storage for primary frequency control support. Int. J. Electr. Power Energy Syst. 2015, 68, 313-326. [CrossRef]

15. Zhang, X.; Li, Z.; Su, C.Y.; Lin, Y.; Fu, Y. Implementable Adaptive Inverse Control of Hysteretic Systems via Output Feedback with Application to Piezoelectric Positioning Stages. J. IEEE Trans. Ind. Electron. 2016, 63, 5733-5743. [CrossRef]

16. Delille, G.; François, B.; Malarange, G. Dynamic Frequency Control Support by Energy Storage to Reduce the Impact of Wind and Solar Generation on Isolated Power System's Inertia. J. IEEE Trans. Sustain. Energy 2012, 3, 931-939. [CrossRef]

17. Gonzalez-Longatt, F.M.; Bonfiglio, A.; Procopio, R.; Verduci, B. Evaluation of inertial response controllers for full-rated power converter wind turbine (Type 4). In Proceedings of the Power and Energy Society General Meeting, Boston, MA, USA, 17-21 July 2016.

18. Ju, L.; Wei, Y.; Jinyu, W.; Ma, R. Prospect of Technology for Large-Scale Wind Farm Participating into Power Grid Frequency Regulation. J. Power Syst. Technol. 2014, 38, 638-646.

19. Kiaee, M.; Cruden, A.; Infield, D. Utilisation of Alkaline Electrolysers to Improve Power System Frequency Stability with a High Penetration of Wind Power. J. Renew. Power Gener. IET 2014, 8, 529-536. [CrossRef]

20. Wuchang, D.; Jianguo, W.; Tanxi, X. Estimation of Battery State of Charge Based on Neural Network. J. Northeast Electr. Power Univ. 2016, 36, 1-6.

21. Johnston, L.; Díaz-González, F.; Gomis-Bellmunt, O.; Corchero-García, C.; Cruz-Zambrano, M. Methodology for the economic optimisation of energy storage systems for frequency support in wind power plants. J. Appl. Energy 2015, 137, 660-669. [CrossRef]

22. Cheng, M.; Sami, S.S.; Wu, J. Benefits of using virtual energy storage system for power system frequency response. Appl. Energy 2017, 194, 376-385. [CrossRef]

23. Jin, T.; Yingchen, Z. Coordinated Control Strategy of a Battery Energy Storage System to Support a Wind Power Plant Providing Multi-Timescale Frequency Ancillary Services. J. IEEE Trans. Sustain. Energy 2017, 8, 1140-1153.

24. Dang, J.; Seuss, J.; Suneja, L.; Harley, R.G. SOC feedback control for wind and ESS hybrid power system frequency regulation. In Proceedings of the 2012 IEEE Power Electronics and Machines in Wind Applications (PEMWA), Denver, CO, USA, 16-18 July 2012.

25. Wang, Y.; Bayem, H.; Giralt-Devant, M.; Silva, V.; Guillaud, X.; Francois, B. Methods for Assessing Available Wind Primary Power Reserve. J. IEEE Trans. Sustain. Energy 2015, 6, 272-380. [CrossRef] 
26. German EON Power Grid Corp. Available online: http://www.eon.com/ (accessed on 20 March 2018).

27. Shupeng, J.; Ying, Q.; Fei, X.; Sciubba, E. Capacity Optimization and Sensitivity Analysis of Cogeneration System of Wind Power and Energy Storage. J. Autom. Electr. Power Syst. 2013, 37, 16-21.

28. Yupeng, X.; Zhinong, W.; Guoqiang, S.; Sun, Y.; Shen, H.; College of Energy and Electrical Engineering, Hohai University; Wuxi Power Supply Company; Jiangsu Electric Power Company. Life Cycle Cost Based Optimal Configuration of Battery Energy Storage System in Distribution Network. J. Power Syst. Technol. 2015, 39, 264-270.

29. Zhao, H.; Wu, Q.; Hu, S.; Xu, H.; Rasmussen, C.N. Claus Nygaard Rasmussen, Review of energy storage system for wind power integration support. Appl. Energy 2015, 137, 545-553. [CrossRef]

2018 by the authors. Licensee MDPI, Basel, Switzerland. This article is an open access article distributed under the terms and conditions of the Creative Commons Attribution (CC BY) license (http://creativecommons.org/licenses/by/4.0/). 